\title{
UMA PROBLEMATIZAÇÃO ACERCA DO CONCEITO DE MIGRAÇÃO. APONTAMENTOS NA PRODUÇÃO HISTORIOGRÁFICA DO ESTADO DE RONDÔNIA ${ }^{1}$
}

\author{
Cátia Franciele Sanfelice de Paula² \\ Célia Rocha Calvo ${ }^{3}$
}

RESUMO: O presente artigo tem como objetivo problematizar o conceito de migração com base na produção historiográfica produzida sobre o Estado de Rondônia. Ao tratá-lo como um conceito histórico, buscamos levantar questões que possibilite a compreensão e o diálogo com aspectos amplos que compõem o processo social a ser estudado. Assim, busca-se apontar possíveis caminhos que viabilize abordagens de caráter investigativo.

PALAVRAS-CHAVE: Historiografia. Migração. Rondônia.

ABSTRACT: This article aims to discuss the concept of migration based on historical production produced about the State of Rondônia. To treat him as a historical concept we seek to raise questions that allows understanding and dialogue with broad aspects that make up the social process to be studied. Thus, if point possible paths that enable investigative character approaches.

KEYWORDS: Historiography. Migration. Rondônia.

1 O projeto de pesquisa que resultou neste artigo contou com financiamento da CAPES/FAPERO.

2 Mestre em História, professora do Departamento de História da Universidade Federal de Rondônia, Campus Rolim de Moura. Doutoranda em História Social pela Universidade Federal de Uberlândia.

3 Professora do Instituto de História e Coordenadora do Núcleo de Pesquisa em História, Cidade e Trabalho. (NUPHECIT) da Universidade Federal de Uberlândia-MG. 
A historiografia sobre Rondônia é composta em sua maioria por pesquisas nas áreas da Geografia e Sociologia. As concepções teóricas que explicam o local, principalmente o fluxo migratório àquele Estado, se estruturam em diversos conceitos, como o de migração, que naturalizado confere à análise historiográfica um caráter estruturalista e economicista sobre o processo histórico. Nessa perspectiva, as linhas de argumentação se pautam nas análises das políticas adotadas pelo governo militar que desencadearam projetos de colonização a partir da década de 1970, as quais acabam por incorporar e fortalecer marcos de memória social (CALVO, 2005) ligados aos processos de construção da BR 364 ou de órgãos criados no período como a SUDAM (Superintendência de Desenvolvimento da Amazônia), SUDENE (Superintendência de Desenvolvimento do Nordeste), e INCRA (Instituto Nacional de Colonização e Reforma Agrária). Ainda está presente uma interpretação que atribui o processo migratório à modernização conservadora ${ }^{4}$ do campo, ocorrida no Sul do Brasil, às propagandas do governo militar ou aos supostos benefícios proporcionados pelo capital privado, sem, porém, especificar quais seriam esses grupos beneficiados (SOUZA; GROSSI, 2010).

Nesta direção, o objetivo do artigo é problematizar como o conceito de migração inviabiliza, quando pensado nesses termos, a compreensão de aspectos mais amplos, como a relação com os lugares e com as cidades que se constituíram no decorrer desse processo de idas e vindas de muitos agentes que vieram para Rondônia. Busca-se ainda, apontar caminhos que possibilite a problematização do conceito, compreendendo-o não como um conceito analítico, mas histórico, isto é, apreendido como problema, no processo e nos procedimentos de investigação social (FENELON, 2009; WILLIAMS, 1977).

Inicialmente, há que ressaltar que a maior parte das pesquisas apresentam abordagens que homogeneízam as especificidades dos municípios que compõem o Estado, como se as relações

4 Sobre modernização conservadora, ver: MOREIRA, 2012. 
tivessem ocorrido do mesmo modo em todos os lugares. Pautada em uma visão cíclica sobre o processo histórico, o que por sua vez remete à uma ideia de evolução ao evidenciar "novos ciclos" econômicos, é como se houvesse uma história anterior a 1970, em referência ao ciclo da borracha, e outra que após 1970 se firmou com os projetos de colonização e com o desenvolvimento da agropecuária. Nessa versão, os projetos relativos à agropecuária estariam em processo de transição para novos ciclos materializados na industrialização, na plantação de outras culturas como a soja que está vinculada à dinâmica extensiva do agronegócio e, de produção de energia elétrica a partir de projetos de construção de Hidrelétricas e PCHs (Pequenas Centrais Hidrelétricas).

Em outras abordagens, identificamos denúncias sobre os problemas que o Estado passou a enfrentar frente ao insucesso da política migratória, a qual não teria tido a capacidade de sanar as demandas por terra (SOUZA; PESSOA, 2009). Embora não desconsideramos que a política de colonização tenha ocasionado uma série de conflitos agrários, questiona-se, porém, o fato de que os mesmos não são analisados em sua historicidade, isto é, como processo histórico. Por outro lado, é frequente a ideia de que antes de 1970 não houve problemas em Rondônia. Ou ainda, que os problemas após 1970 teriam se intensificado (TURCHI, 1981).

Analisando tais trabalhos, as homogeneizações são muitas e não explicam efetivamente as contradições no processo histórico em que os projetos de colonização foram elaborados e implantados, tampouco questões relativas ao movimento histórico anterior. Desse modo, como forma de buscar a historicidade destas categorias analíticas, seus significados e alterações, problematizamos a historiografia a partir de autores que se debruçaram em compreender o período anterior a 1970. Nesta produção, encontramos diversos elementos conflitantes desde o início do século $X X$, que por sua vez reaparecem em outros contextos, sem a devida historicidade, como é o caso das tentativas de se construir colônias agrícolas no início do século, depois em 1930 e 1940 e posteriormente, em 1970, quando são 
elaborados pelo INCRA os projetos de colonização com intuito de promover com maior intensidade a "ocupação".

Maciel (1999) em sua pesquisa sobre a Comissão Rondon buscou discutir questões relativas à construção das linhas telegráficas nas primeiras décadas do século XXe, as interpretações, imagens e significados elaborados por engenheiros, militares e técnicos sobre os "sertões". Dentre a riqueza da abordagem oferecida pela autora, algumas questões nos ajudam compreender as homogeneizações presentes nos trabalhos analisados que se reportam ao contexto da década de 1970. Um primeiro elemento a ser destacado é o discurso de "espaço vazio". Tal slogan está presente em diversos trabalhos e sem historicidade dá a entender que se remete ao contexto de 1970 quando constatamos que o mesmo foi utilizado como justificativa à ocupação desde o início do século XX, reafirmados nos anos 1930, 1940 e em 1970:

Compreendendo o interior do país como um vasto espaço vazio, em branco, habitado por populações ainda "arredias a civilização", que representam barreiras ou limites ao avanço da República, os engenheiros militares ligados a Comissão Rondon defendiam a necessidade de ocupar esses espaços e dilatar as "fronteiras da Pátria", como um dever do Estado a ser conduzido pelo exército "as forças armadas da nação". (MACIEL, 1999 página 168).

Para Maciel, a noção de "vazio" possui relação com a ausência de uma população disciplinada, tentada desse modo pela Comissão Rondon. No dizer da autora, tomava corpo a ideia de que "governar era povoar". A autora ressalta que se deve atribuir à Comissão não a busca pelo "novo" ou do caráter de descoberta, mas o papel de ordenadora do território, com empenho em outro tipo de ocupação e aproveitamento das terras e a pacificação das relações entre os vários atores sociais. Ao acompanhar o desfecho desse processo histórico encontramos elementos na década de 30, com o trabalho de Souza (SOUZA, 2002), os quais Maciel havia apontado em seu trabalho, quando afirmou que "buscar a historicidade destas categorias permite 
acompanhar o processo de alteração de seus significados e, ainda, sua eficácia para a hierarquização dos espaços - físicos e sociais - internos e externos" (MACIEL, 1999, p.187).

Ao analisar a ação dos militares e os debates em torno da construção do Território Federal de Rondônia, nos anos 1930 e 1940 do século XX, Souza (SOUZA, 2002) abordou os projetos de ocupação implementados pelo Exército a fim de compreender sua atuação, a partir de uma análise que buscou no movimento histórico analisar o período anterior a 1930, pontuando como os projetos implantados antes desse período serviram como base para os projetos que seriam desenvolvidos posteriormente:

O Posto Telegráfico tinha diversas atribuições como o levantamento do potencial mineral, do potencial agropecuário, estudo de flora e fauna, além de manter contato com os povos indígenas da região e ir "limpando" o caminho para os colonizadores que viriam a seguir. (SOUZA, 2011, p. 12).

Nessa análise, temos a evidência de que ocorreram tentativas de colonização anteriores à década de 1970. Tanto o trabalho de Maciel quanto o de Souza apontam nesse sentido, como já vinham sendo gestadas. Em 1930 há a continuidade da política de "ocupação", a partir da infraestrutura formada pela Comissão Rondon. Souza destaca que em 1930 foi tentada a implantação de colônias agrícolas nas regiões de Porto Velho e Guajará Mirim. Porém, a tese levantada pelo autor é a de que não houve sucesso devido a problemas como o tamanho dos lotes, a infertilidade das terras, a falta de política de preços e a ausência de assistência técnica. A infertilidade das terras está ligada invariavelmente ao fato de que a instalação dos núcleos agrícolas se dava em pontos estratégicos do ponto de vista militar, que possibilitasse a defesa da fronteira (SOUZA, 2002). De acordo com Souza, os núcleos agrícolas seriam a saída para o extrativismo na década de 1930 , momento em que a produção da borracha, que apresentava grandes custos passou a ser valorizada devido à demanda pelo produto no mercado internacional. 
A abordagem feita por Souza nos permite observar outra questão ausente da historiografia analisada. $O$ fato de que houve um grande fluxo de pessoas que se dirigiram ao Estado no segundo ciclo da borracha e, posteriormente, com a descoberta da cassiterita na década de 1950. Porém, Souza remete esse processo a uma abordagem cíclica, e como resultante tanto da criação do Território Federal ${ }^{5}$, quanto da criação do Estado de Rondônia6:

[...] tem-se a "Batalha da Borracha" que desembocou num surto efêmero de colonização e a consequente criação do Território Federal do Guaporé. Depois disso, a descoberta de cassiterita redundaria na abertura da então BR-29 no governo de JK em 1960. E por último o ciclo da colonização agropecuária entre as décadas de 70 e 80 como sendo um dos fatores que contribuíram para a transição para o Estado em 1981. (SOUZA, 2002, p. 6).

Assim como a descoberta da cassiterita o processo de mecanização ocorrido em 1971 também fica oculto na historiografia. Segundo Souza, a mecanização teria ocorrido devido à pressão exercida por alguns consórcios de empresas mineradoras que resolveram explorar a região em relação ao Governo Federal, a fim de fechar a lavra manual e regulamentar à lavra mecanizada. Porém, de acordo com informações presentes no Jornal Correio da Manhã7, de 1971, o objetivo do governo Federal na época era explorar o máximo possível de cassiterita tendo como finalidade a exportação.

A mecanização da cassiterita teria provocado enormes prejuízos à economia do Território ${ }^{8}$, afetando também setores

5 A criação do Território Federal de Rondônia ocorreu em 1943.

6 A criação do Estado de Rondônia ocorreu em 1981.

7 Disponível em: <http://memoria.bn.br/DocReader/Hotpage/HotpageBN.aspx?b $i b=089842$ _08\&pagfis=15975\&pesq=\&url=http://memoria.bn.br/docreader\#>.

8 Maiores informações, ver: SOUZA, Valdir Aparecido de. (Des)ordem na fronteira: ocupação militar e conflitos sociais na bacia do Madeira-Guaporé 
como transporte, alimentação, comércio e serviços em geral. Souza ainda discute a maneira como nesse período havia disputas políticas em torno da administração do Território entre o exército que administrou o território por cinquenta anos e pelas coligações de oposição (União Democrática Nacional e Partido Social Progressista). Porém, o autor não aprofunda essa discussão. Esse quadro de disputa política teria durado até a descoberta da cassiterita e sua posterior mecanização, o que fez com que o exército perdesse a popularidade no Território.

Diante dessas reflexões consideramos que o trabalho de Maciel e Souza explicitam que o processo de ocupação não é fruto unicamente da década de 1970, como pontua grande parte da historiografia. $E$ que os últimos elementos a impulsionar a ocupação para Rondônia teriam sido a descoberta da cassiterita e o projeto agropecuário com incentivo fiscal às empresas de capital estrangeiro destinado à exportação, nas décadas de 19701980, sob a direção dos governos militares (SOUZA, 2002). Com base em um contexto de discurso nacionalista, a Amazônia como um todo era vista como um lugar a ser explorado. Assim, uma questão de suma importância e que justifica a análise realizada neste ensaio é buscar no movimento histórico a compreensão de como foram pensados e elaborados os projetos de colonização na década de 1970. Nesta direção, não podemos desconsiderar o processo de transformação que ocorria em outros Estados e suas inter-relações.

Partimos do princípio de que, sob a política integracionista, cujo lema "Integrar para não entregar", estiveram presentes outros objetivos, os quais o termo "integração" não nos permite apreender. O termo "integração" consiste em um conceito ideológico que, ao buscar justificar os projetos em curso, não explica as contradições que ocorriam no campo das relações sociais.

Nesse contexto, constituíram-se explicações sociológicas no campo historiográfico que, ao realizarem uma abordagem pautada

(30-40). 2002. Dissertação (Mestrado em História)-Faculdade de Ciências e Letras, Universidade Estadual Paulista “Júlio de Mesquita Filho", Assis, 2002. 
na concepção desenvolvimentista, se cristalizaram no interior da academia, oferecendo discussões que vão ao encontro dos discursos governamentais do período, reproduzindo conceitos como o de integração e migração sem a devida problematização, conferindo ao Estado o protagonista e perdendo de vista as relações sociais.

Ambas as pesquisas evidenciam uma série de questões conflitantes anteriores à década de 1970. Souza, porém, busca entender o processo histórico a partir de dados oficiais, pautados ora na construção da estrada de ferro madeira Mamoré, na criação do Território Federal, na implantação de colônias agrícolas ou nos projetos de nacionalização preconizados por Vargas, na qualidade de marcos políticos explicativos daquilo que ocorria no período. Do mesmo modo, a historiografia cuja abordagem procurou compreender Rondônia após 1970, se firmou em dados oficiais, estabelecendo marcos de memória como forma de justificar os acontecimentos advindos com a implantação dos projetos de Colonização.

O fato é que se o discurso de "espaço vazio" foi utilizado para justificar a ocupação no início do século XX como apontado por Maciel, na década de 1970, a justificativa de ocupar os vazios continua junto ao discurso de integração das fronteiras. A ênfase na ocupação foi divulgada por diversos meios de comunicação e podemos perceber sua dimensão a partir da reportagem "Cirne Lima diz que ocupação da Amazônia é necessária e viável”, noticiada no Jornal Alto Madeira:

O SR. Cirne Lima definiu como, "indispensável" a ocupação real do território nacional, acentuando que a marcha para o Oeste, iniciada pelos bandeirantes, ainda é muito pouco efetiva, exigindo um esfôrço nacional para atingir tal objetivo, "que é mais urgente quando se analisa as condições mundiais da produção de alimentos e os índices elevadíssimos de crescimento demográfico". Ao argumento de que só se deve aplicar no litoral, onde há uma infraestrutura que é capaz de oferecer rendimento compensador aos investimentos públicos e privados, respondeu o Ministro Cirne Lima 
que a ocupação da Amazônia não exigiria grandes quantidades de capital, uma vez que a terra ali é barata e o Brasil possui mão-deobra não qualificada o suficiente para dar início efetivo à ocupação, "não como deve mas sim como pode ser feita". (ALTO MADEIRA. Porto Velho, p. 1, 1 maio 1970).

As projeções elencadas pelo então Ministro da Agricultura para aquela região, desconsiderou elementos básicos para os que para lá se deslocaram, como estradas, habitação, saúde, educação, dentre outros. Embora houvesse o reconhecimento da realidade que estava colocada, fica clara a projeção em relação a quem daria início à ocupação - pessoas cuja mão de obra não fosse qualificada.

Além disso, a noção de desenvolvimento e progresso no período se alicerçou em uma noção de cultura padrão, e na maioria das interpretações o Estado passou a existir em termos de povo, de vida e de cidade com a vinda dos migrantes, numa concepção de que os deslocamentos é que traria cultura e os que chegavam seriam portadores do desenvolvimento e do progresso esperado.

As noções de civilização, progresso e cultura que fizeram parte do processo de disputa em torno dos projetos de nação não ficaram restritas ao período do Estado Novo. Elas reaparecem ou nunca estiveram fora da pauta das preocupações governamentais tornando-se visíveis em 1970. Se até as décadas de 1940/1950 os indígenas eram vistos como possíveis trabalhadores "nacionais", nas colônias agrícolas nas décadas de 1970 e 1980 passam a ser totalmente desconsiderados como parte daquela localidade.

A partir da década de 1980, constatamos por meio do jornal $O$ Globo, a ênfase aos que se dirigiam ao Estado, provenientes da região Sul do país, como aqueles que seriam responsáveis pela formação de uma futura cultura padrão, como podemos observar na reportagem "Governador Jorge Teixeira de Oliveira afirma que crise não atinge a economia de Rondônia": 
No aspecto cultural, é interessante observar que a migração vem de todos os pontos. Essas crianças que estão nascendo aqui em Rondônia, e que, no futuro, vão se aproximar, formarão amanhã uma nova raça de Rondônia. O rondonienese surgirá daqui a 20 anos, complementando os que já haviam aqui. Será um raça forte, por que os troncos são também muito fortes: o paranaense, o nordestino, o gaúcho. Isso vai dar um padrão de cultura. Os costumes vão se difundir, e dessa mistura surgirá até uma nova linguagem. Aqui terá uma espécie de esperanto (esperança). Eu vislumbro um futuro muito grande para Rondônia, pois os outros estados estãi acumulando problemas enquanto aqui estamos começando. (O GLOBO. Rio de Janeiro, p. 2, 30 jun. 1983).

A desconsideração da cultura nativa se colocava junto à projeção de uma noção de cultura que atribuía a determinadas etnias um modelo padrão. Como se fosse possível buscar por uma cultura autônoma. Nesta direção, a historiografia ao não problematizar essas noções e atribuir ao processo histórico o conceito de migração incorporou tais aspectos e manteve juntos todos aqueles que chegavam, no mesmo patamar de pioneirismo, consagrando inclusive a política adotada pelo INCRA, que, em seus projetos, também manteve juntos trabalhadores de diversos lugares, os quais trouxeram em suas "bagagens" culturais diferentes expectativas e projetos de vida. Ao congelar o processo histórico, tal memória torna ocultas essas diversidades e diferenças, na medida em que homogeneíza os sujeitos e suas diferenças socioculturais.

Nessas produções, as lutas e disputas travadas no cotidiano diário são pouco perceptíveis. Nelas não há espaço para a complexidade do que acontecia no dia a dia, porque cumprem um papel na produção de memórias que se requer autorizada a falar do passado e do presente, a ser a história. Nessas versões, os conflitos não existem, os sujeitos eleitos a fazer parte dela invariavelmente ocupam lugar de destaque. Nelas, o ordenamento estabelecido entre passado e presente deixa poucos espaços para se pensar outras possibilidades de análise. 
Outro aspecto observado é que tais narrativas se perpetuam na produção de memorialistas, cujas produções edificam genealogias, efemeridades que se transformam em marcos que ocultam tantos outros personagens do cotidiano do trabalho.

Dessas versões é que surgem os mitos como o de pioneiro e o de desbravador, como se fosse possível quantificar as lutas e sofrimentos e auferir através de um denominador comum quem mais sofreu e é merecedor de estar na memória e na história. Nessa memória há a tentativa de retratar as dificuldades dos que chegaram e tiveram que viver em localidades sem saúde, educação e habitação, em meio à mata fechada etc. Porém, nessa narrativa a memória e a história são elaboradas tendo como base um passado comum a todos materializado num presente também comum, de vitórias e conquistas, sem espaço para as disputas e contradições. Assim, tanto a historiografia, quanto os livros de memorialistas se tornam versões cristalizadas ${ }^{9}$.

Nesta direção, o conceito de migração precisa ser colocado em movimento, numa relação em que a noção de processo histórico esteja aberta às investigações e descobertas. Antes de ser explicado por ele mesmo o conceito precisa ser posto a problematizações tendo em vista o momento histórico que se quer investigar, buscando romper desse modo, com a ideia determinista de causa e consequência. Partimos da prerrogativa de que as relações sociais são complexas e contraditórias e que pautá-las em análises dicotômicas em nada contribui para a compreensão do processo histórico, haja vista que os conceitos, em si, não explicam as relações vivenciadas.

É por este caminho que sinalizamos para o entendimento da História Social, como história-problema e não como descrição de certezas, como campo de interpretações, sem que elas signifiquem verdades objetivas ou métodos de validade universal. A História Social define o seu campo de reflexão ao formular problemas que ajudam a interpretar as relações entre os diversos grupos sociais, o que significa trazer para o campo da reflexão

9 Sobre essa crítica, ver também: LANGARO, 2012. 
histórica aqueles que são referidos apenas como coadjuvantes, quando o são: mulheres, trabalhadores rurais e urbanos, idosos, grupos subalternos dentre outros.

Consideramos que, se o objetivo é explicitar questões sobre o social pautado em experiências dos sujeitos que vivenciam o processo histórico a ser estudado, o diálogo com materiais de natureza diversa e, também, a produção de fontes orais se coloca dentre as possibilidades de problematizar versões cristalizadas e, ao mesmo tempo, conferir visibilidade aos diferentes agentes que se puseram em movimento no processo de constituição do território de Rondônia.

Interessa, pois refletir sobre a experiência social dos diversos agentes para que os mesmos se revelem como sujeitos do e no processo histórico. Os registros que produziram e os significados que elaboraram acerca da realidade vivida, também precisam ser considerados como elementos que levaram à migração. Só a partir dessa análise encontramos evidências que ajudarão na problematização e compreensão do processo histórico de forma ampla.

Daí a importância da memória como força ativa e como, por intermédio dela, evidenciamos questões relativas ao passado. Para isso, as contribuições trazidas pela História Social ajudam refletir sobre qual o papel da historiografia, em especial, da história no diálogo com a sociedade ao questionar sobre qual história estamos escrevendo, para quem e como ela está dialogando com o social.

Nesta discussão, as contribuições de Fenelon (FENELON, 2004) no que se refere a constituição das memórias é significativa em termos de evidenciar os diversos significados atribuídos pelos sujeitos as suas vivências, na dinâmica construída em torno de suas experiências de modo mais amplo. Falar de memória, como lembra Khoury (KHOURY, 2004), é entendê-la como um espaço onde as diferenças se constituem, portanto não estão dadas. Tais diferenças precisam ser compreendidas como sendo de classe ${ }^{10}$,

10 Segundo Edward Palmer Thompson, classe social consiste em um fenômeno histórico definida pelos homens enquanto vivem sua própria história. Conforme: THOMPSON, 1987. 
não no sentido fechado do termo, mas culturalmente vivida na maneira como os sujeitos se requerem diante do processo de desigualdade que vivem. Ou seja, a partir dos sentidos e significados que os sujeitos atribuem a sua experiência social. Para isso, é de fundamental importância considerar o modo como relacionam os sentidos do tempo e da temporalidade na relação passado e presente. Isso perpassa compreender as memórias enquanto práticas socioculturais, articuladas as relações de poder presentes no cotidiano, compreendido como um tempo de contradições vividas, interpretadas e significadas pelos sujeitos enquanto um processo de mudanças em movimento e em transformação.

Esta perspectiva sugere romper com noções cristalizadas e a constante problematização dos conceitos utilizados no processo de pesquisa, o que impõe ao pesquisador considerar o processo de constituição das fontes, independentemente de sua natureza. Enquanto produto social, as fontes disponíveis ao historiador precisam ser tratadas de modo relacional e num constante processo de disputas.

De modo específico às fontes orais, não se trata de descrever as experiências dos sujeitos e seus modos de vida, mas inserir a discussão dentro de um processo amplo que explique os projetos que estavam colocados e as alternativas disponíveis em cada período histórico. Atentar-se para a forma de elaboração e, de construção das narrativas pode revelar aquilo que aponta Portelli quando diz que "A organização narrativa da vida cotidiana nos diz algo sobre onde está o sentido desta vida" (ALMEIDA; KHOURY, 2014, p. 205).

Outras contribuições estão na perspectiva de problematizar os conceitos a luz da prática social de modo a operacionaliza-los no movimento histórico. Isso implica o desafio teórico-metodológico discutido por Cruz (CRUZ, 2006) e o Grupo Memória Popular (GRUPO MEMÓRIA POPULAR, 2000) sobre a relação: passado e presente na história. Essas discussões evidenciam ao mesmo tempo a função social e política da história e do historiador e o cuidado para a não despolitização da história. De acordo com 
Cruz (CRUZ, 2006), é necessário ter claro qual a preocupação com o presente e o que nos leva indagar o passado. Isso implica repensar qual o diálogo que estabelecemos quando elegemos protagonistas para estudarmos nossos temas e problemas, o que por sua vez também implica repensar que os procedimentos metodológicos adotados devam ser menos de juntar fontes, e mais de problematizar seu processo de constituição de modo que não esteja desprovido do processo social.

Nesta perspectiva, a cultura é pensada como espaço de luta e não apenas modo de vida, e os mecanismos presentes na sociedade, como as linguagens, precisam ser compreendidos não no sentido abstrato, mas como práticas constitutivas e ativas da vida social. Portanto, a memória não é só representação, mas significados atribuídos pelos sujeitos em sua vida prática. No trabalho com a memória, o sentido de determinado passado possui relação com questões colocadas no presente porque são constitutivas e mediadas socialmente e culturalmente por ele.

Por isso, a necessidade de pensá-las a partir do movimento histórico e das temporalidades vividas pelos sujeitos, evidenciando elementos que podem ser responsáveis por determinadas narrativas, como valores ou a incorporação de memórias instituídas. Pensar assim, as diversas temporalidades tendo em vista que os sujeitos significam de modo diferente suas relações.

Por ser a memória compreendida enquanto uma dimensão constitutiva da consciência social dos sujeitos a história oral não consiste em apenas um recurso no trabalho do historiador para confirmar ou buscar informações que não estão presentes em outros recursos. Seu uso possibilita a percepção do passado no momento em que é ativado no social e, desse modo, explicita significados que não se restringe a ela mesma, mas ao seu processo de elaboração e, portanto, ao processo histórico vivido pelos sujeitos.

Quando esses supostos são desconsiderados o trabalho com a memória leva a análises que se reportam ou a um presente imediato ou a um passado no qual não se visualiza questões relativas ao presente. Assim, pensar os sujeitos e suas 
problemáticas implica pensar cultura. A fonte oral é um processo, uma prática social, na qual o sujeito não interpreta deslocado da vida real. Ele significa no campo da cultura, algo que não foi criado pelo pesquisador, mas a partir de valores construídos durante sua trajetória. Daí a importância de pensar as diferenças durante o processo de análise das entrevistas orais, pois as diferenças significam fronteiras vivenciadas socialmente. Tratase menos do que foi dito pelo sujeito, interessando a noção de processo durante a elaboração da fala, o que o sujeito traz e o modo como se apropria dos significados dominantes disponíveis num determinado contexto como forma de organizar seus pensamentos, a construção de seu enredo e os silêncios que podem estar contidos. Como menciona Portelli "A primeira coisa que torna a história oral diferente, portanto, é aquela que nos conta menos sobre eventos que sobre significados" (PORTELLI, 1997, p. 31).

A partir desses supostos, a problematização do conceito de migração permite a pesquisa histórica um referencial de análise pautado nas experiências dos sujeitos que vivenciaram tal processo. Sujeitos que narram suas trajetórias de vida e de trabalho a partir de seus referenciais e, que através deles nos possibilitam compreender o contexto de mudanças vivenciadas. Mudanças nas formas de viver e trabalhar provocadas por transformações estruturais e de reorganização nos modos de viver suas relações no campo e na cidade.

Para isso, faz-se necessário ao historiador compreender o conceito de migração em sua historicidade sem restringir seu sentido aos deslocamentos tampouco caracterizá-lo a partir de explicações estáticas. Sua historicidade precisa ser posta a luz do processo histórico a ser analisado e vivenciado pelos sujeitos, o que pode evidenciar outros elementos não presentes em análises fechadas sobre tal processo.

Assim, compreendemos que a historiografia analisada requer novas perguntas às evidências e talvez uma delas seja questionar em que medida os marcos de memória estabelecidos permitem as descobertas. Ou, em que medida a produção historiográfica 
produzida estabelece um diálogo com a sociedade a ponto de explicitar algo muito importante para nós historiadores e ressaltado por Déa Fenelon:

Outra vez esta idéia bastante rica para nós historiadores de que o nosso objeto é a transformação, a mudança, o movimento, o interesse em saber como e por que as coisas aconteceram, principalmente para descobrir o significado e a direção da mudança. (FENELON, 2009, p. 35).

A historiografia sobre Rondônia não parece avançar e como pontua Rama (RAMA, 2015) busca imprimir uma lógica por meio das estruturas que tem servido mesmo sem querer aos interesses da cidade letrada. Ela requer novas perguntas por que entendemos que enquanto prática social a historiografia intervém em nosso presente e passado.

Desse modo, analisar o processo histórico a partir de marcos de memória não oferece saída para uma análise satisfatória acerca das ações frente ao que estava sendo vivenciado pelos sujeitos sociais. Isto porque os marcos de memória eleitos pela historiografia se reportam as agências que pontuaram o processo de expansão do Território e depois do Estado, tendo como pano de fundo as políticas de colonização. Por isso a importância de interrogar sobre qual processo conduziu às políticas de colonização a partir de uma relação mais ampla, na qual outros valores e significados podem estar colocados.

É necessário considerar, que tal processo não pode ser analisado de modo que esteja atrelado às questões de ordem política ou econômica apenas. A leitura que os sujeitos fazem e os significados acerca da realidade também precisam ser considerados como elementos que levaram à migração. Nos trabalhos analisados, por exemplo, inexiste a preocupação de construir uma interpretação com base na problematização das relações sociais e das experiências dos sujeitos. Uma questão importante para a História Social no que se refere à compreensão 
do processo histórico a partir das práticas sociais. Todas essas questões ampliam a compreensão do campo social, político e cultural que se denominou como migração.

As abordagens analisadas oferecem formas de interpretação que congelam o processo histórico, impossibilitando o entendimento de questões relativas às experiências, aos modos de vida e de trabalho daqueles que vivenciaram tal processo histórico. Algumas versões continuam se perpetuando com a naturalização de conceitos que obscurecem as experiências, não permitindo a compreensão sobre quais sujeitos se fala. Isso impossibilita a visibilidade das disputas ocorridas passando a ideia de um processo tranquilo. Há que destacar que, passadas várias décadas, são aos mesmos referenciais ${ }^{11}$ a que se recorre nas abordagens sobre o processo migratório. Nesse sentido, ao evidenciar estas questões o objetivo não é identificar possíveis lacunas deixadas pela historiografia, mas explicitar que o caminho traçado por ela vem servindo a consagração de versões dominantes.

No diálogo com esta produção historiográfica e memorialística, outra possibilidade que se coloca é a de explicitar as questões relativas às lutas e os embates para compreender como os projetos foram materializados na prática, e, talvez, mais importante do que constatar como a produção historiográfica silenciou relações contraditórias é perceber como pontua Williams (WILLIAMS, 2011) além da historicidade dos conceitos utilizados, o porquê de sua persistência.

11 Entre os principais referenciais, podemos citar: IANNI, O. Colonização e contra-reforma agrária na Amazônia. Petrópolis: Vozes, 1979. (Coleção Sociologia Brasileira, v. 11); BECKER, B. K. Amazônia. São Paulo: Ática, 1990. (Série Princípios); BECKER, Berta K.; MIRANDA, Mariana; MACHADO, Lia O. (Orgs). Fronteira amazônica. Questões sobre a gestão do Território. Rio de Janeiro: Ed. UFRJ, 1990; VALVERDE, Orlando (Coord.). A organização do espaço na faixa da Transamazônica. Rio de Janeiro: Ministério da Agricultura; Instituto Nacional de Colonização e Reforma Agrária. 1979. V. 1: Sudoeste Amazônico, Rondônia e regiões vizinhas. 


\section{Referências:}

ALMEIDA, Paulo Roberto de; KHOURY, Yara Aun. História oral e memórias. Entrevista com Alessandro Portelli. História \& Perspectivas, Uberlândia, n. 50, p. 203-214, jan./jun, 2014.

BECKER, Berta K.; MIRANDA, Mariana; MACHADO, Lia O. (Orgs). Fronteira amazônica. Questões sobre a gestão do Território. Rio de Janeiro: Ed. UFRJ, 1990.

BINSZTOK, Jacob; ERTHAL, Rui; TUBALDINI, Maria Aparecida; DEUS, José Antonio Souza de; MACEDO Giovanni Raimundo de. Projetos integrados de colonização: paradigma da contra-reforma agrária promovida pelo regime militar nos anos 70 na Amazônia. Disponível em: <http://www.uff.br/vsinga/trabalhos/CC/Projetos $\% 20$ Integrados $\% 20$ de\%20Coloniza\%E7\%E3o.pdf>.

CALVO, Célia R. et alii: Trabalho e movimentos sociais: histórias, memórias e produção historiográfica. In: MACHADO, Maria Clara Tomaz; CARDOSO, Heloísa Helena Pacheco (Orgs.). História: narrativas plurais, múltiplas linguagens. Uberlândia: EDUFU, 2005.

CARDOSO, Fernando Henrique; MULLER, Geraldo. Amazônia: expansão do capitalismo. São Paulo: Brasiliense, 1977.

CRUZ, Heloísa de Faria et al. Introdução. In: MACIEL, Laura Antunes et alii (Orgs). Outras histórias: memórias e linguagens. São Paulo: Olho D’Água, 2006.

FENELON, Déa Ribeiro et alii. Muitas memórias, outras histórias. In: (Orgs.). Muitas memórias, outras histórias: São Paulo: Olho D’Água, 2004.

FENELON, Déa Ribeiro. Cultura e História Social. Projeto História, São Paulo, n. 10, 1993. 
FENELON, Déa Ribeiro. Estado, poder e classes sociais. Revista Brasileira de História. São Paulo, n. 7, 1984.

FENELON, Déa Ribeiro. O historiador e a cultura popular: história de classe ou história do povo? História \& Perspectivas, Uberlândia, n. 40, p. 27-51, jan./jun. 2009.

FENELON, Déa Ribeiro. Trabalho, Cultura e História Social: perspectivas de investigação. Projeto História, São Paulo, n. 4, 1985.

GRUPO MEMÓRIA POPULAR. Memória popular: teoria, política, método. In: FENELON, Déa Ribeiro et alii (Orgs.). Muitas memórias, outras histórias. São Paulo: Olho D’Água, 2004.

IANNI, O. Colonização e contra-reforma agrária na Amazônia. Petrópolis: Vozes, 1979. (Coleção Sociologia Brasileira, v. 11).

IANNI, O. Ditadura e agricultura. O desenvolvimento do capitalismo na Amazônia. Rio de Janeiro: Ed. Civilização Brasileira, 1979.

KHOURY, Yara Aun. Muitas Memórias, outras histórias: cultura e o sujeito na história. In: FENELON, Déa Ribeiro et alii (Orgs.). Muitas memórias, outras histórias. São Paulo: Olho D’Água, 2004.

LANGARO, Jiani F. Quando o futuro é inscrito no passado. "Colonização" e "pioneirismo" nas memórias públicas de Toledo-PR (1950-2010). 2012. Tese (Doutorado em História Social)-Programa de Estudos PósGraduados em História, Pontifícia Universidade Católica de São Paulo, São Paulo, 2012.

MACIEL, Laura Antunes. A Comissão Rondon e a conquista ordenada dos sertões: espaço, telégrafo e civilização. Projeto História, São Paulo, n. 18, maio. 1999. Disponível em: <http://revistas.pucsp.br/index.php/ revph/article/view/10994/8114>. 
MACIEL, Laura Antunes. A nação por um fio. Caminhos, práticas e imagens da "Comissão Rondon". São Paulo: EDUC, 1998.

MARTINS, José de Souza. A militarização da questão agrária no Brasil. Petrópolis: Vozes, 1984.

MOREIRA, Vagner José. A produção agropecuária: trabalho e resistência. Perspectiva Geográfica, Marechal Cândido Rondon-PR, v.7, n. 8, 2012.

OLIVEIRA, A. U. Integrar para entregar: políticas públicas e Amazônia. Campinas: Papirus, 1988.

PORTELLI, Alessandro. Forma e significado na História oral. A pesquisa como um experimento em igualdade. Projeto História, São Paulo, n. 14, fev. 1997.

PORTO Gonçalves, C. W. Amazônia, Amazônias. São Paulo: Contexto, 2001.

RAMA, Angel. A cidade das letras. São Paulo: Boitempo, 2015.

SARLO, Beatriz. Um olhar político. In: . Paisagens imaginárias. São Paulo: Edusp, 1997.

SOUZA, Murilo Mendonça Oliveira de; GROSSI, Suely Regina Del. A regionalização do espaço amazônico: o caso de Rondônia. Revista da Católica, Uberlândia, v. 2, n. 3, p. 126-135, 2010. Disponível em: <http:// catolicaonline.com.br/revistadacatolica2/artigosv2n3/10-Geografia.pdf>.

SOUZA, Murilo Mendonça Oliveira de; PESSÔA, Vera Lúcia Salazar. A contra-reforma agrária em Rondônia: Colonização agrícola, expropriação e violência. Encontro de Grupos de Pesquisa, 5., 2009, Santa Maria. Agricultura, desenvolvimento regional e transformações socioespaciais. Anais eletrônicos... Santa Maria: UFSM, 2009. Disponível em: <http:// w3.ufsm.br/gpet/engrup/vengrup/anais/1/Murilo\%20Mendonca_NEAT UFU.pdf>. 
SOUZA, Valdir Aparecido de. (Des)ordem na fronteira: ocupação militar e conflitos sociais na bacia do Madeira-Guaporé (30-40). 2002. Dissertação (Mestrado em História)-Faculdade de Ciências e Letras, Universidade Estadual Paulista “Júlio de Mesquita Filho”, Assis, 2002.

SOUZA, Valdir Aparecido de. Rondônia, uma memória em disputa. 2011. Tese (Doutorado em História)-Faculdade de Ciências e Letras, Universidade Estadual Paulista "Júlio de Mesquita Filho", Assis, 2011.

THOMPSON, Edward P. A formação da classe operária inglesa. Rio de Janeiro: Paz e Terra, 1987.

TURCHI, Maria Lenita. A colonização dirigida no processo de expansão e ocupação da fronteira agrícola: território federal de Rondônia. Encontro Nacional de Estudos Populacionais, 2., 1980. Anais... s/l: ABEP, 1981. Disponível em: <http://www.abep.nepo.unicamp.br/docs/anais/pdf/1980/ T80V01A07.pdf>.

VALVERDE, Orlando (Coord.). A organização do espaço na faixa da Transamazônica. Rio de Janeiro: Ministério da Agricultura; Instituto Nacional de Colonização e Reforma Agrária. 1979. V. 1: Sudoeste Amazônico, Rondônia e regiões vizinhas.

WILLIAMS, Raymond. Base e superestrutura na teoria cultural marxista. In:__ Cultura e materialismo. São Paulo: Editora Unesp, 2011. p. 43-68.

WILLIAMS, Raymond. O campo e a cidade: na história e na literatura. São Paulo: Companhia das Letras, 2011.

Recebido em julho de 2016. Aprovado em janeiro de 2017. 